\title{
Simple model of megalopal transport in narrow river-dominated estuaries
}

\author{
Stephen A. Borgianini ${ }^{1, *}$, Richard Styles ${ }^{2}$, Renae J. Brodie ${ }^{3}$ \\ ${ }^{1}$ Department of Mathematics and Sciences, University of South Carolina Beaufort, Bluffton, South Carolina 29909, USA \\ ${ }^{2}$ U.S. Army Corps of Engineers, Coastal and Hydraulics Laboratory, Engineer Research and Development Center, Vicksburg, \\ Mississippi 39180, USA \\ ${ }^{3}$ Department of Biological Sciences, Mount Holyoke College, South Hadley, Massachusetts 01075, USA
}

\begin{abstract}
In river-dominated estuaries such as Winyah Bay at the base of the Pee Dee River in South Carolina, USA, the net movement of water and pelagic larvae is toward the ocean. Larvae of many decapods are hypothesized to recruit back into estuaries using a complex behavior termed flood-tide transport (FTT). A pattern of late-stage larval behaviors in concert with daily tidal rhythms yields net larval transport upstream into the estuary. Tidal currents in narrow river channels exhibit little distortion of flow, resulting in near linear flows. This means that there is a linear decay in tidal current amplitude over the last few kilometers of the upper estuary that can be easily modeled with a simple 1-dimensional (1D) model. With our 1D model, we demonstrate that ebb and flood currents can be modeled accurately near the limit of maximum upstream tidal influence within narrow river-dominated estuaries. Our model predicts the damping of flood tidal current in the face of river discharge. This dampening restricts the upriver migration potential of larvae that use FTT to return to adult habitats, or colonize new habitat. When our model is coupled with FTT behavior, we can predict the ability of red-jointed fiddler crab Uca minax (LeConte 1855) larvae to recruit back to the freshwater reaches of the Pee Dee River estuary for any combination of river discharges or tidal amplitudes. The flow model we developed can be used to assess the potential impacts of changing river flow and sea level on larval recruitment to upstream areas of coastal rivers.
\end{abstract}

KEY WORDS: Larval transport - Decapod larvae - Tidal currents - River discharge - Tidal freshwater $\cdot$ Modeling $\cdot$ Uca minax $\cdot$ Global warming

\section{INTRODUCTION}

Understanding the mechanisms that enhance or inhibit larval recruitment is critical to determining adult distribution and population dynamics of a given species (Roughgarden et al. 1988), especially in marine and estuarine systems. Many coastal and estuarine species with complex life histories migrate from estuarine/freshwater habitats to nearshore waters during their life cycle (Strathmann 1982). Early-stage larvae are less able to tolerate highly variable salinity and oligohaline conditions than are adults (Anger 2001, 2003, Charmantier et al. 2001, Brodie et al. 2007). In some decapod crustaceans that occupy freshwater habitats, larvae hatched there are rapidly transported downstream to nearshore waters where physiological stress and predation pressure is reduced (e.g. Christy 1982, Christy \& Stancyk 1982, Morgan 1987, Morgan \& Christy 1995). In these nearshore waters, zoeae undergo several molts and eventually metamorphose into post-larval megalopae. These megalopae 
then recruit to freshwater, upriver areas where they settle into parental habitats and metamorphose into juveniles.

Decapod megalopae are hypothesized to use floodtide transport (FTT; e.g. Cronin \& Forward 1979, 1986, De Vries et al. 1994, Olmi 1994, Forward \& Tankersley 2001, Tankersley et al. 2002) to recruit back to adult habitat against the flows that exported the zoeae to the continental shelf. Under this process, the megalopae settle on the bottom during ebb tide and swim vertically into the water column during nocturnal flood tides; their net transport is upstream into the estuary. This model of recruitment would work well for well-mixed, tidally dominated estuaries where ebb- and flood tidal flow are not significantly different from each other. However, the FTT model would be insufficient in river-dominated estuaries that have significant net downstream flow, such as Winyah Bay in South Carolina (USA). Here, periodically large river flow can dampen the intensity and duration of upriver tidal flow, especially in the narrower, upper river channels. Tidal currents in these narrow river channels are amplified by topographic funneling of these currents into the fluvial geometry of the rivers.

Such narrow river channels (width:depth <10) exhibit little distortion of flow, due to low shear along the banks resulting in near linear flows. The result is a linear decay in tidal current amplitude over the last few kilometers of the upper estuary. Therefore ebb and flood currents near the limit of maximum upstream tidal influence can be visualized accurately within narrow estuaries as a simple, 1-dimensional (1D) system. The near 1-dimensionality of this system is of extraordinary consequence to marine larvae, as the overwhelming majority of larvae are moving, en masse, in the water column as FTT predicts. We developed a 1D flow model for the narrow freshwater portion of the Pee Dee River that is affected by tides before its discharge into Winyah Bay. When our model is coupled with megalopal migration behavior predicted by the FTT model, we can estimate the potential for megalopae to penetrate the upper reaches of the Pee Dee River for various river discharges or tidal amplitudes.

The point where the tidal velocity amplitude equals the discharge velocity defines the maximum upriver excursion of passive particles. However, the FTT model predicts that megalopae move upriver by rising into the water column only on nocturnal flood tides. Obviously, the intensity and duration of the flood current varies both with tidal cycle and location along the river.
In Winyah Bay near Georgetown, South Carolina, the effects of changing river flow (upstream diversion and eustatic sea level rise) will have an impact on the recruitment for megalopae of red-jointed fiddler crabs Uca minax (LeConte 1855) to freshwater upriver areas where they settle into adult habitats and metamorphose into crabs. In South Carolina, U. minax first-stage zoea larvae are released into the water column in adult habitats on nocturnal ebbing spring tides during the months of May through September. The hatchlings actively swim near the surface during ebb tides to move down-estuary (S. A. Borgianini pers. obs.) and presumably into coastal marine waters where development continues. $U$. minax larvae pass through 5 zoeal stages, then metamorphose into post-larval megalopae, which enter an estuary and actively swim during nocturnal flood tides to move inland where settlement and a second metamorphosis to the first crab stage occurs. Larvae experience significant salinity variation on this migration. Even though Uca megalopae are hypothesized to use FTT to recruit back into estuaries (e.g. Christy 1982, Brookins \& Epifanio 1985, Little \& Epifanio 1991, DeVries et al. 1994, Christy \& Morgan 1998), recruitment behaviors associated with FTT may not be sufficient to regularly recruit to all adult habitats in a lengthy system like the Pee Dee River.

Here we applied our coupled flow/behavior model of larval transport to assess empirical Uca minax adult distribution observed along the Pee Dee River. Like other fiddler crabs, U. minax is a euryhaline species; however, robust populations of adults are found more than $80 \mathrm{~km}$ from the sea along the banks of tidally influenced freshwater streams and rivers discharging into Winyah Bay (S. A. Borgianini pers. obs.). This oligohaline to freshwater distribution is atypical for fiddler species, which generally prefer mesohaline and euhaline salinities (Crane 1975). U. minax is found at locations significantly upriver from Winyah Bay in each of the 4 rivers that discharge into the estuary, despite significant net downriver flow into Winyah Bay. Additionally, the distribution of $U$. minax on the Waccamaw River-Pee Dee River system with the Winyah Bay estuary is such that $U$. minax megalopae migrating upriver encounter more than $50 \mathrm{~km}$ of suitable settlement habitat that currently has viable conspecific adult populations. The physical, biological, behavioral, and developmental factors affecting the apparent distribution of $U$. minax are not well understood. Our aim was to identify the physical and biological factors that affect recruitment and thereby limit the distribution of $U$. minax populations in the freshwater reaches of tidal rivers. $U$. 
minax has a relatively immobile adult phase. Site fidelity is high, and adults do not migrate significant distances from the habitats in which they originally settled as post-larvae (Teal 1958). It therefore follows that if adult $U$. minax are present, they arrived at that location as megalopae that migrated upriver utilizing FTT. Indeed, previous work suggests that larval metamorphosis of Uca spp. is significantly correlated with adult habitat (O'Connor \& Gregg 1998, O'Connor \& Judge 2004, Behum et al. 2005, Brodie et al. 2005, O'Connor \& Van 2006).

Our primary study objective was to show that a simple linear 1D particle transport model, when coupled with larval vertical migration behavior, can be used to estimate upstream migration potential of marine larvae in a narrow estuary with a strong tidal signal and significant river discharge. Additionally, we validated these model estimates by comparing actual adult Uca minax distribution along the Pee Dee River to model predictions of upriver megalopal penetration.

\section{MATERIALS AND METHODS}

\section{Model development}

We have recently explored the interaction between discharge and tidal forcing in producing the net flows along the length of the Pee Dee River, in central South Carolina (Fig. 1). The Pee Dee has a large drainage basin and is the major source of freshwater input to Winyah Bay, a large partially mixed estuary (Goni et al. 2003).

In the upper freshwater reaches of the estuary, the narrowness of the channel produces a net water movement that is mostly along the river axis. Certainly for the issue of larval transport, the critical movement of larval movement is along this axis; therefore, we chose the most direct model for estimating this flow, whereby we effectively treated the narrow upriver water as a 1D movement along the axis of the river. When a larva is swimming within the water column, it will be transported either upriver or downriver, depending on the interaction between the downstream discharge and the upstream velocity driven by tidal amplitude.

Under high discharge conditions, the upper estuary behaves like a river. Currents are directed downstream as flooding tide cannot overcome the discharge velocity. Under low discharge conditions, the current is reversed when the flood tide overwhelms the river flow and water is pushed upriver. The crosssectional area of the boundary layer of river banks and bottom were treated as negligible relative to the total mass of moving water produced by these larger patterns. These assumptions allow for a simple, but powerful analytical model to predict the potential upriver migration of larvae in a system where flow is a balance between river discharge and tidal amplitude.

From a purely physical perspective, the upper estuary has received little attention in terms of the coupled effect of discharge and tidal forcing. Recent theoretical work by Horrevoets et al. (2004) has begun to examine the role of discharge in modulating tidal dynamics near the limit of maximum upstream tidal influence. Their modeling study indicated that increases in river discharge tend to (1) dampen the tidal range in the upper estuary and (2) cause the location of the tidal boundary (the maximum landward extent of tidal influence) to shift seaward. Horrevoets et al. (2004) showed that the upstream point

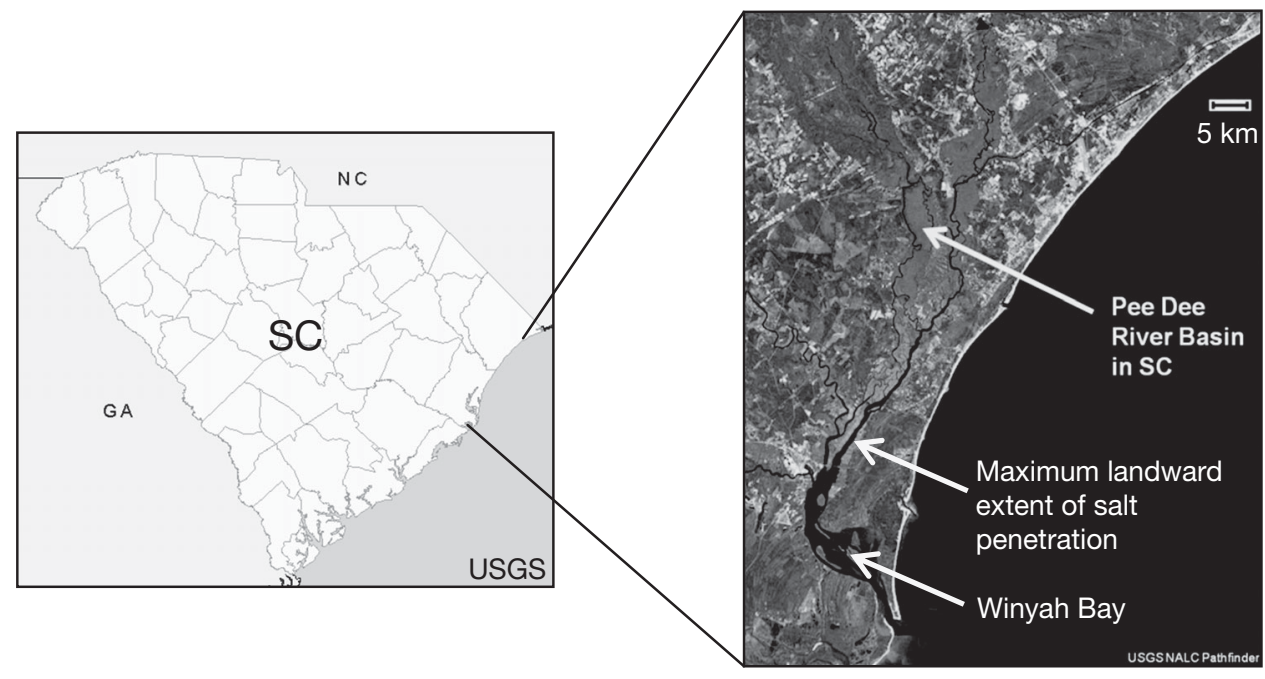

Fig. 1. Lower Pee Dee River located in central South Carolina (SC), USA. This portion of the river discharges into Winyah Bay, a large partially mixed estuary. The aerial image denotes the upper estuary; the region of salt penetration and tidal influence 
of tidal influence is modified by discharge via frictional forces. This means that river discharge inhibits upstream transport by damping the tidal signal, effectively modulating the domain of tidal influence in the upper estuary. The degree of tidal influence is directly related to the upriver transport potential of megalopae.

Between October 2004 and July 2005, a total of 7 acoustic Doppler current profiler (ADCP) deployments were conducted in the freshwater reaches of the Pee Dee River (Fig. 2). These deployments allowed us to collect actual on-river flow measurements that could be used to develop the basic passive

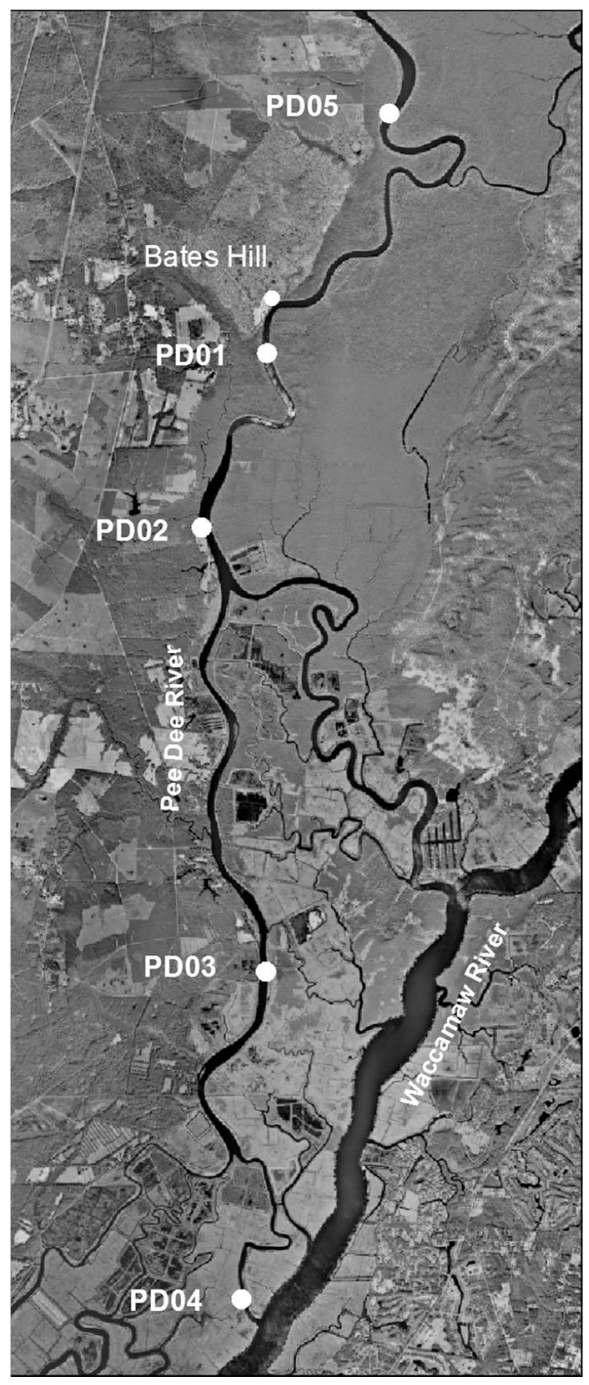

Fig. 2. Acoustic Doppler current profiler (ADCP) deployment locations (stations) along the Pee Dee River in the Winyah Bay Estuary, South Carolina. Freshwater populations of UCa minax were located throughout this portion of the river/estuary system. Bates Hill Plantation (PD01) was the reference location for all ADCP deployments. The US Geological Survey (USGS) station (PD06) is upriver of PD05 particle transport model. The basic particle transport model was given some measure of biological reality by imbuing the particles with 'behaviors' that simulated the putative vertical migration behavior that Uca minax megalopae would exhibit if they employed the FTT strategy. Deployments were scheduled in such a manner as to bracket the spring phase of the local lunar tidal cycle. Data collection spanned $7 \mathrm{~d}$ so that the maximum tidal amplitude (and resultant flood tidal current) occurred on Day 3 or 4 of the collection (see Table 1 for deployment locations, durations, and instrumentation). We selected the spring tidal phase because it represents the largest variations in water level and associated current speeds. As we are modeling the maximum penetration of larvae, the spring tides represent the maximum upstream larval migration opportunity. Additionally, the model is sensitive to the tidal current amplitude linearly, so the spring/neap variation is not critical with regard to the model's applicability.

Each deployment (excluding the first) consisted of paired profiling stations at preselected locations along the Pee Dee River (Fig. 2). The locations were selected to coincide with points near the upriver tidal boundary landward of the salt intrusion (maximum landward extent of the salt penetration). Additionally, the profiling stations were positioned in sections of the river where the channel was comparatively straight and uniform in cross section. The model spanned the Pee Dee River from its confluence with the Waccamaw River (Station PD04) to the large oxbow just south of Lower Topsaw Landing (PDO5; $\left.33^{\circ} 36^{\prime} 25^{\prime \prime} \mathrm{N}, 79^{\circ} 09^{\prime} 00^{\prime \prime} \mathrm{W}\right)$. This section of the Pee

Table 1. Acoustic Doppler current profiler (ADCP) deployment locations and instrumentation. ADCP: RDI ${ }^{\circledR} 1200 \mathrm{kHz}$, ADP: Sontek ${ }^{\circledR} 600$ kHz. For locations see Fig. 2

\begin{tabular}{|ll|}
\hline Date & \multicolumn{1}{c|}{ Station } \\
\hline 20-28 February 2004 & PD01 - ADCP \\
18-26 May 2005 & PD01 - ADCP \\
& PD02 - ADP \\
18-25 May 2005 & PD01 - ADCP \\
& PD02 - ADP \\
2-9 June 2005 & PD01 - ADCP \\
20-28 June 2005 & PD03 - ADP \\
18-25 July 2005 & PD01 - ADCP \\
& PD04 - ADP \\
2-8 August 2005 & PD01 - ADCP \\
& PD05 - ADP \\
& PD01 - ADCP \\
& PD03 - ADP \\
\hline
\end{tabular}


Dee River has relatively few branches, so our assumption of uniform discharge and simplification to $1 \mathrm{D}$ is fitting when addressing larval movement in the face of upriver/downriver flow. On each deployment, one of the paired profiling stations was always positioned at Bates Hill Plantation (PD01) to provide a common reference location. The other stations (PD02, PD03) were used to help calibrate the model and to define the along-river gradients of the current amplitude.

For correlative purposes concurrent to our ADCP deployments, time series of currents and water level data were acquired from the US Geological Survey (USGS) gauge monitoring station (02135200) located on the Pee Dee River near the Highway 701 Bridge in Bucksport, Horry County, South Carolina (PD06; $\left.33^{\circ} 39^{\prime} 39^{\prime \prime} \mathrm{N}, 79^{\circ} 09^{\prime} 17^{\prime \prime} \mathrm{W}\right)$. This gauge station was equipped with a bottom-mounted ADCP that provided hourly measurements.

Tidal constituents were obtained from the time series data for each deployment using the T-tide software program, a Matlab ${ }^{\circledR}$ program that performs classical harmonic analysis for periods shorter than 1 yr (Pawlowicz et al. 2002). The river discharge velocity and mean water depth were obtained by averaging the ADCP data for current velocity and water elevation, respectively, during each of the 7 deployments. All reported velocities were rotated into the along-channel direction and represent the depth averaged flow.

For modeling purposes, we assumed that megalopae do not exhibit directional preference in their horizontal swimming behavior and therefore travel passively with currents when in the water column (Christy 1982). Uca minax megalopae appear to alter their position vertically in the water column to exploit the nocturnal flood tidal current and avoid downstream transport during the diurnal and nocturnal ebb tidal phase (Christy 1982, Johnson 1985, Epifanio 1988, Lopez-Duarte \& Tankersley 2009).

The combination of friction and opposing river discharge tends to dampen the magnitude of the tidal velocity, thereby reducing the tidal impact upriver. Assuming river discharges greater than 0 , the net distance upriver that a particle or megalopa can travel during a given tidal cycle will decrease as the particle or megalopa advances up the river. This is a consequence of upstream tidal velocity that decays constantly when opposed by river discharge, such that a megalopa can only take shorter 'steps' upstream as it attempts to return to the upper adult habitats.

\section{Flow and transport model}

Tidal amplitude and river discharge are the 2 main features that characterize the physical dynamics of the tidal freshwater reaches of the Pee Dee River. While the upper estuary includes a substantial tidal component, it is well inland of the salt intrusion so that the effects of density stratification can be neglected; therefore, the water column moves as a cohesive unit.

The physical model to describe the dynamics of the upper estuary is illustrated schematically in Fig. 3. We assumed a tidally influenced river that receives a significant source of freshwater discharge and that is landward of the salt intrusion so that stratification can be neglected. The portion of the Pee Dee River in our modeling regime is relatively narrow; therefore, the longitudinal (along-river) scale of the motion is assumed to be much greater than the lateral (crossriver) scale so that the system can be treated as $1 \mathrm{D}$. We exploited the fact that the model is applied to the region where the tide is vanishing and assumed that the discharge velocity exceeds the amplitude of the tidal current. In illustrating the solution, we allow the discharge velocity to take on a range of values with respect to the tidal velocity amplitude. Justification for relaxing this constraint is seen in the favorable agreement between the model and observations. Because the physical domain is near the maximum upstream extent of tidal influence, the longitudinal scale of the motion $(L)$ must be much smaller than the wavelength of the tide, or

$$
L<<\sqrt{g h_{0}} T
$$

where $g$ is the acceleration due to gravity, $h_{0}$ is average river depth, and $T$ is the tidal period. For the M2 (semidiurnal) tidal constituent in a $3 \mathrm{~m}$ deep river, $L$ must be much less than $243 \mathrm{~km}$. This implies the length scale appropriate for our model is on the order of $10 \mathrm{~km}$. To complete the linear model, $h_{0}$ is assumed to exceed fluctuations in surface elevation. Consider-

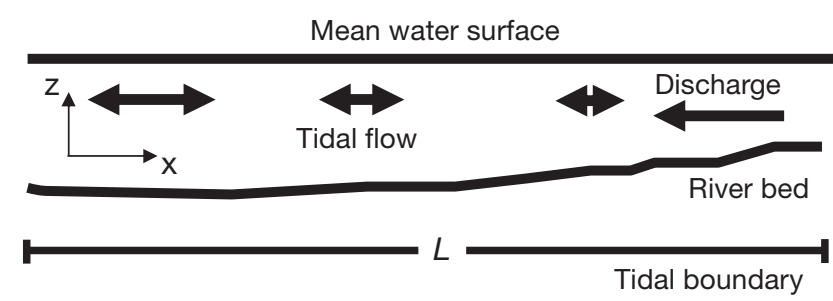

Fig. 3. Physical domain of the upper estuary flow model (Eqs. 2 and 4). We assumed an oscillatory tidal flow that exhibits a linear decay in amplitude over a distance $L$ that terminates at the tidal boundary 
ing that we are applying the model near the tidal boundary, the tidal velocity amplitude will vary along the river and eventually vanish at some point upstream. We further assumed that the river is relatively uniform in cross-section over a distance that a particle (megalopa) could travel in a single tidal cycle. In this way, the model can take into account variations in discharge velocity over a few days and at different positions along the river. With these constraints in mind, the along-channel velocity in the upper estuary is written as

$$
V=-u_{0}+u_{T} \sin (\omega t)
$$

where $V$ is the total along-channel velocity, $u_{0}$ is the discharge velocity, $u_{T}$ is the amplitude of the tidal velocity which can vary as a function of position, $\omega$ is the tidal radian frequency, and $t$ is time. Our coordinate system is oriented so that the along-channel axis is positive upstream, hence the negative sign on the discharge velocity. Near the tidal boundary, we modeled the tidal velocity amplitude as a linear function of position,

$$
u_{T}=u_{\mathrm{a}}\left(1-\frac{X}{L}\right)
$$

where $x$ is the along-channel component of position, and $u_{\mathrm{a}}$ is the amplitude of the tidal velocity at a distance $L$ downstream from the point where the influence of the tide vanishes (Fig. 3).

Noting that $V$ is the time rate of change of position, Eq. (2) can be written as

$$
\frac{\mathrm{d} x}{\mathrm{~d} t}=-u_{0}+u_{\mathrm{a}}\left(1-\frac{x}{L}\right) \sin (\omega t)
$$

Eq. (4) can be integrated to give the particle position as a function of time. Important features of the model include: (1) an analytical solution so that it is possible to physically interpret the relative effect of discharge and tidal forces in controlling the movement of passive constituents, (2) the maximum upstream particle position is proportional to $u_{0} / u_{a}$, (3) the solution depends only on 4 parameters $u_{0}, u_{\mathrm{a}}$ $\omega$, and $L$, which can be measured for a given river system, or determined from historical tide and flow data. Because the initial start position is arbitrary, the model can be run for a single tidal cycle to determine the excursion of a suspended particle. The maximum excursion point at the end of the first tidal cycle can be used as the initial condition for the next run. This cycle can be repeated indefinitely for an arbitrary number of tidal cycles until the particle has left the model domain or has migrated to the maximum upstream point $\left(u_{T} / u_{0}=1\right)$. In this way, we can vary the discharge velocity at the beginning of each new tidal cycle or even in the middle of a tidal cycle. This is a powerful feature as it allows us to start and stop a model run at arbitrary stages of the tide and discharge conditions. As an example, we can run simulations only on flood tide at night to investigate behavioral transport patterns typical of organisms that employ an FTT migration behavior. Alternatively, we can investigate salinity tolerance and survivorship in UCa minax larvae newly released in freshwater by running the model only during ebb tide to determine how long it would take larvae drifting downstream to reach the salt intrusion and thereby increase their chances of survival. Model predictions indicate that downriver travel time of first stage zoeae is sufficient such that they are able to survive the journey to estuarine salinity conditions where they can complete development (sensu Brodie et al. 2007). In addition, developmental constraints such as the duration of the pelagic larval stages of benthic organisms can be incorporated into the model to simulate development-limited maximum upriver migration potential.

\section{Biological verification of model predictions}

In our study, we also planned to verify model predictions by examining the density of Uca minax adults along the section of the Pee Dee River that was modeled. We estimated $U$. minax population densities on the Pee Dee River along a longitudinal river transect that extended from the confluence of the Pee Dee and Waccamaw Rivers to Bates Hill Plantation, $16 \mathrm{~km}$ upriver. We used burrow counts as a proxy for fiddler crab density. Burrow counts have been demonstrated to provide more accurate density estimates than binocular counts (Macia et al. 2001, Skov \& Hartnoll 2001) for some Uca species. During multiple collections on the Pee Dee River, we observed that most probed burrows were occupied. Therefore, counting crab burrows was hypothesized to be a valid estimator of adult $U$. minax population densities along the river.

Permanent sampling locations were selected to correspond to transport model predictions of the distance a megalopa would travel on each successive nocturnal flood tide assuming average tidal amplitude and river discharge conditions. Fourteen stations were sampled along this transect. Burrow counts were recorded in the creek bank-zone at all stations. Sealed burrows were not counted. At each station, 7 replicate burrow density measurements 
were made by counting the number of burrows within a randomly placed $0.25 \mathrm{~m}^{2}$ quadrat. We conducted 3 burrow sampling events: late season 2006 (8 September); early season 2007 (25 May); late season 2007 (13 September).

\section{RESULTS}

\section{Model predictions}

The results of our ADCP data along the Pee Dee River indicate that tidal current amplitude decays linearly over the last few km of the upper estuary. Fig. 3 illustrates tidal velocity amplitude as a function of linear river distance near the tidal boundary of the Pee Dee River. Station locations are identified in Fig. 2. Tidal amplitude was determined from simultaneous time series of current speed for a $7 \mathrm{~d}$ period during a spring tidal cycle. The lower stations were ours, the upper station (PD06) was located on the Pee Dee River near the Highway 701 Bridge in Bucksport, Horry County, South Carolina, and was operated by the USGS (gauge monitoring station 02135200). Tidal amplitude decay can be described as having a linear relationship to river distance $\left(\mathrm{r}^{2}=\right.$ 0.998, Fig. 4) and supports our choice of a linear function to approximate tidal damping in our flow model (Eq. 4). Table 2 presents the data for all ADCP deployments that were used in the validation of the linear behavior of our model across multiple locations and deployments.

Figs. 5 \& 6 illustrate model output for different tidedischarge scenarios. Fig. 5 depicts the particle trajectory over 1 complete tidal cycle for 0 discharge.

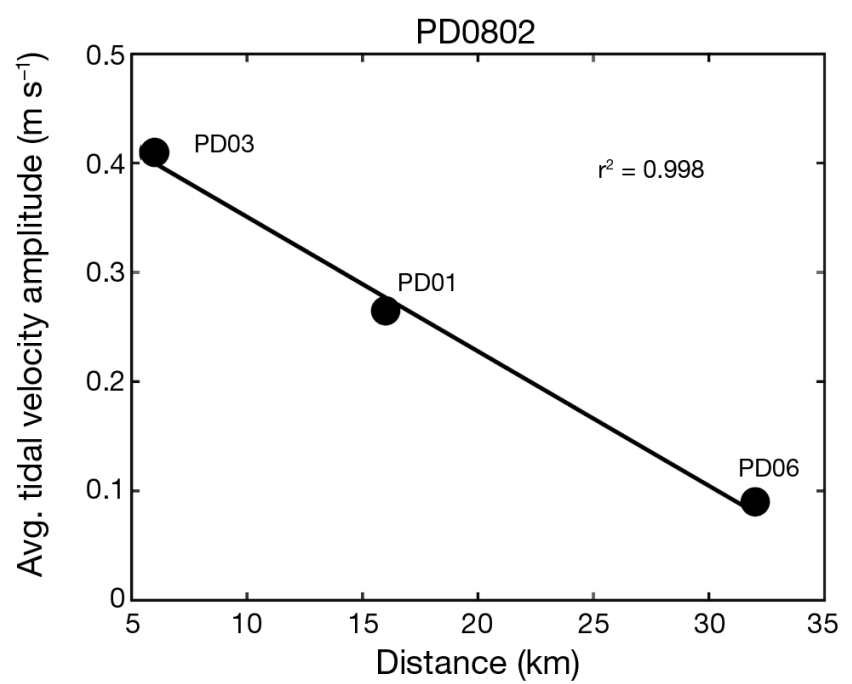

Fig. 4. Tidal velocity amplitude as a function of along-river distance near the tidal boundary of the Pee Dee River. For location of stations see Fig. 2

Because of the along-channel gradient in the tidal velocity, the maximum particle excursion is asymmetric with respect to the starting point. As the particle moves upriver, it encounters weaker tidal flow as the tidal amplitude is decreasing. As it moves downriver, it encounters stronger flow as the tidal amplitude is increasing.

Fig. 6 shows how a particle (in our case, a megalopa) moves upriver by only riding the flood tide under low and high discharge conditions. Note that the upriver excursion is controlled by the magnitude of the discharge velocity, with higher discharge limiting the maximum upriver distance. Only for 0 discharge does the particle reach the tidal boundary, i.e.

Table 2. Measured input parameters for model verification: Slope: the along-channel velocity gradient; $f$ : friction factor; $u_{\mathrm{a}}$ : tidal velocity amplitude; $u_{0}$ : average along-channel current speed, $h_{0}$ : average water depth; $L$ : distance downstream from the point where the tide vanishes. Error limits denote $90 \%$ level of significance. Bates Hill: Station PD01; USGS station, PD06. For location of stations see Fig. 2

\begin{tabular}{|llccccccc|}
\hline Parameter & & 24 Oct 04 & 20 Feb 05 & 18 May 05 & 2 Jun 05 & 20 Jun 05 & 18 Jul 05 & 2 Aug 05 \\
\hline Slope & $\left(\mathrm{m} \mathrm{s}^{-1} \mathrm{~km}^{-1}\right)$ & -0.0139 & -0.0135 & -0.0128 & -0.0133 & -0.0105 & -0.0145 & -0.0132 \\
$f\left(\mathrm{~s}^{-1}\right)$ & $\times 10^{-3}$ & $3.2 \pm 0.4$ & $3.8 \pm 0.5$ & $6.5 \pm 0.8$ & $1.4 \pm 0.2$ & $12 \pm 1.4$ & $4.5 \pm 0.5$ & $3.3 \pm 0.4$ \\
$u_{\mathrm{a}}\left(\mathrm{ms}^{-1}\right)$ & Bates Hill & 0.31 & 0.30 & 0.38 & 0.27 & 0.43 & 0.36 & 0.26 \\
& USGS & 0.10 & 0.06 & 0.20 & 0.11 & 0.20 & 0.14 & 0.08 \\
$u_{0}\left(\mathrm{~ms}^{-1)}\right)$ & Bates Hill & 0.23 & 0.36 & 0.14 & 0.29 & 0.16 & 0.24 & 0.31 \\
& USGS & 0.32 & 0.45 & 0.26 & 0.39 & 0.26 & 0.37 & 0.43 \\
$h_{0}$ & Bates Hill & 3.9 & 2.8 & 4.1 & 3.2 & 3.6 & 2.9 & 4.1 \\
& USGS & 3.5 & 3.4 & 3.1 & 3.4 & 3.1 & 3.2 & 3.3 \\
$L(\mathrm{~km})$ & Bates Hill & 34 & 15 & 57 & 22 & 43 & 24 & 9 \\
& USGS & 11 & 8 & 12 & 9 & 13 & 9 \\
\hline
\end{tabular}




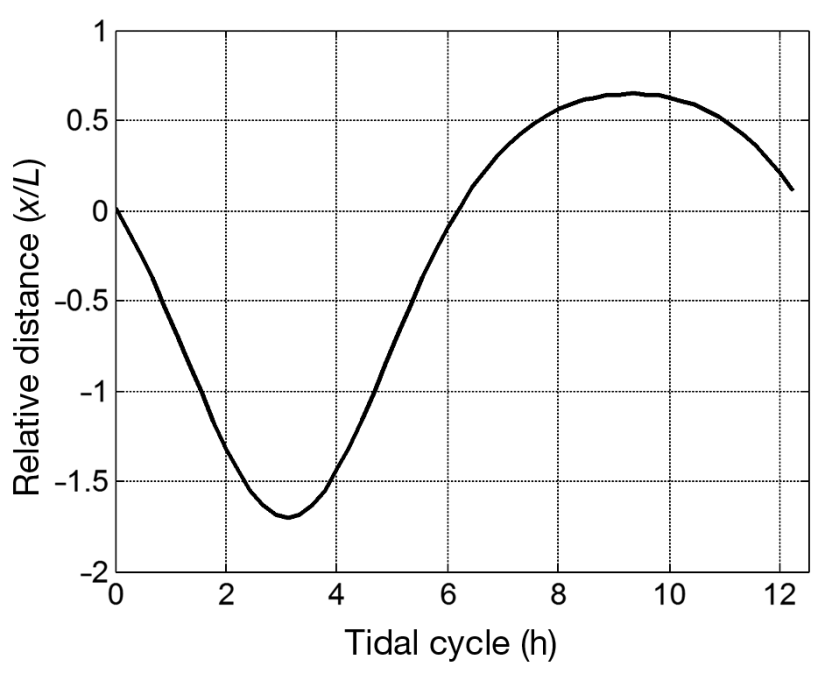

Fig. 5. Particle trajectory over 1 complete tidal cycle with 0 discharge. The $y$-axis denotes relative distance $(x / L)$ traveled from the starting point. Note that during the first half of the tidal cycle, the particle moves downstream a distance greater than $L$, but during the second half it only reaches $0.6 L$ upstream. This is due to the fact that the tidal current increases in the downstream direction

the point where $x=L$. In our study, the tidal boundary was determined mathematically by measuring tidal height at $\geq 2$ points that were known distances apart along the upper part of the river, then fitting a line between the points. Where the line crosses the $x$-axis $(y=0)$ is the distance upstream that the tide vanishes $(L)$. Geographically, the location of $L$ will vary depending upon the tidal amplitude.

Fig. 7 illustrates the transport model predictions of the potential distances a megalopa could travel up the Pee Dee River given certain river flow versus tidal amplitude assumptions. For these model simulations, we used historical discharge and tidal amplitude data. We also assumed that megalopae only travel on nocturnal flood tides (sensu Lopez-Duarte and Tankersley 2009). Given no other limitations on transport, the model predicts that during extremely low flow conditions and high tidal amplitude conditions $\left(u_{0} / u_{\mathrm{a}}=0.9\right)$, a megalopa could be advected as far as $36 \mathrm{~km}$ upriver. During average discharge and average tidal amplitude conditions $\left(u_{0} / u_{\mathrm{a}}=0.5\right)$, the maximum upriver migration potential of a megalopa is $15 \mathrm{~km}$. During high discharge

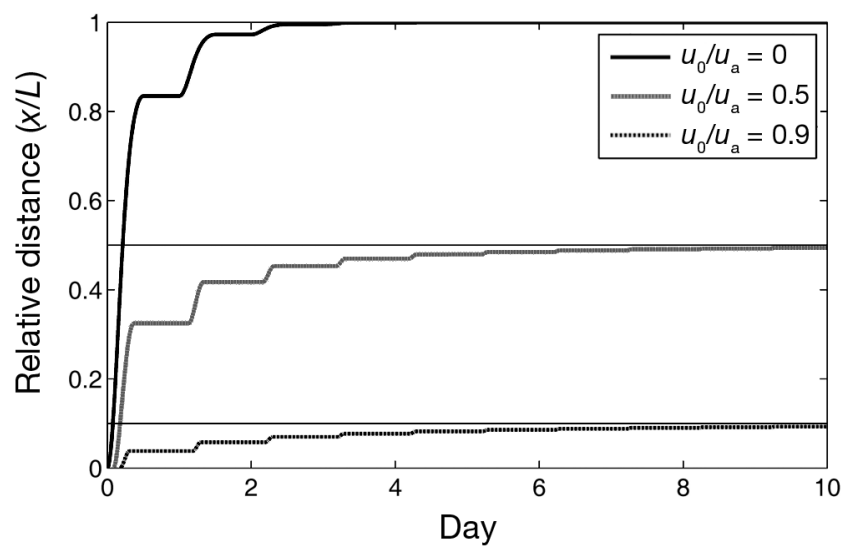

Fig. 6. Particle trajectories as a function of different discharges assuming transport only during flood tide. The $y$-axis denotes relative distance $(x / L)$ traveled from the starting point. The point $x / L=1$ denotes the location of the tidal boundary. Note that as discharge increases, the maximum upstream distance decreases. $u_{0}$ : discharge velocity, $u_{\mathrm{a}}$ : amplitude of tidal velocity

and low tidal amplitude conditions $\left(u_{0} / u_{\mathrm{a}}=0.1\right)$, a megalopa would make little progress upriver. For all other simulations, the maximum upriver excursion is limited by the relative discharge velocity and is equal to $1-u_{0} / u_{\mathrm{a}}$. The net distance traveled during a given tidal cycle also decreases as the megalopa advances up the river. This is a consequence of the decaying tidal velocity, such that the particle (megalopa) takes shorter and shorter 'steps' as it is trying to gain its maximum possible upstream excursion.

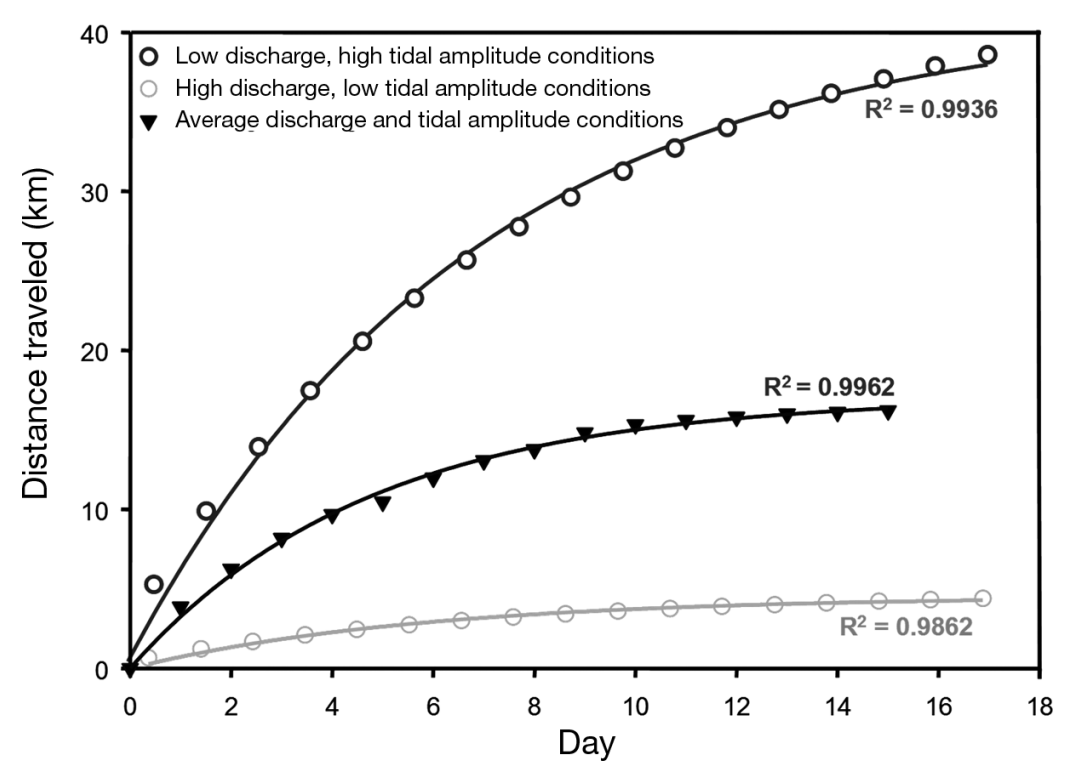

Fig. 7. Model-derived maximum potential upriver distances that a megalopa could travel given 3 different river discharge vs. tidal amplitude scenarios. The $y$-axis represents model-derived river distances traveled by a megalopa 
Because one of the applications of the transport model is to study selective transport used by organisms, the simulation depicts upriver FTT by assuming that the megalopa rides the nocturnal flood tide over many consecutive tidal cycles. The saltatory 'stair step' pattern is a consequence of 0 transport during ebb and diurnal flood tides, when megalopae presumably sink to the bottom and remain at a fixed location.

\section{Biological field verification of model predictions}

We compared the model's predictions of the maximum inland incursion of Uca minax megalopae to what we actually observed in the field in terms of adult distribution. U. minax megalopae must reach adult habitats in sufficient numbers, and with sufficient regularity, to maintain viable adult populations. Model simulation output predicts that megalopal supply should be relatively consistent downstream and then drop off dramatically when the upriver transport potential of the flood current is exhausted. Therefore, if the transport model is sufficiently predictive of upriver migration potential of megalopae, the adult distribution in terms of population density should decrease significantly upriver.

There is a steep decreasing cline in burrow densities which begins approximately $8 \mathrm{~km}$ from the confluence of the Pee Dee and Waccamaw Rivers. Onriver densities of Uca minax continue to drop as one progresses upriver. Downriver populations of adult $U$. $\operatorname{minax}(0$ to $8 \mathrm{~km}$ ) were relatively stable, averaging $\geq 70$ burrows $\mathrm{m}^{-2}$ for all 3 sampling events. Contrast-

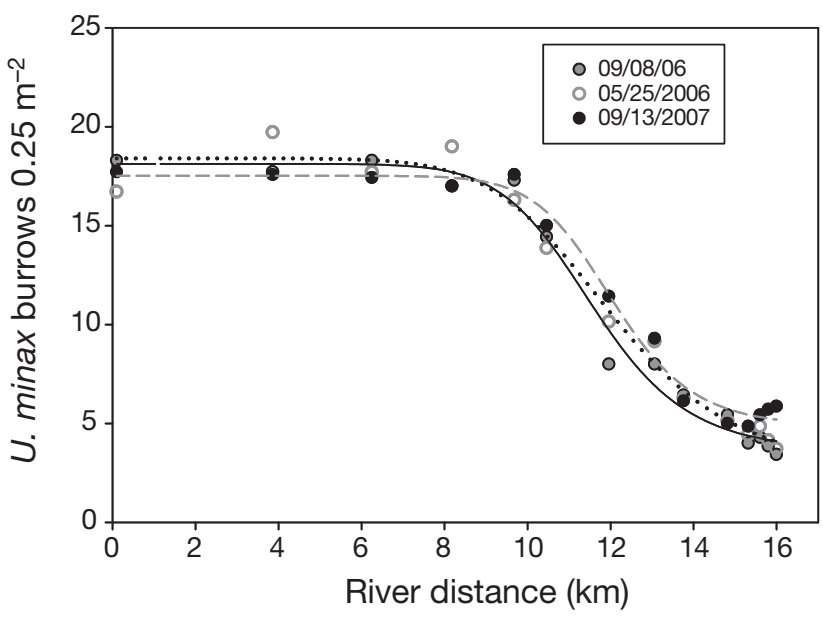

Fig. 8. Uca minax. Adult distribution gradient (burrow count) along the Pee Dee River over 2 seasons. Dates are month/day/year
Table 3. Comparison of nonlinear regression model of UCa minax distribution in the Pee Dee River over 2 seasons. $\mathrm{ED}_{50}$ : river distance at which the upriver Uca minax burrow density has decreased $50 \%$ from downriver burrow density

\begin{tabular}{|lccc|}
\hline Date & $\mathrm{r}^{2}$ & $\mathrm{ED}_{50}$ & $\mathrm{SE}\left(\mathrm{ED}_{50}\right)$ \\
\hline September 8, 2006 & 0.828 & $12.03 \mathrm{~km}$ & 0.265 \\
May 25, 2007 & 0.838 & $11.60 \mathrm{~km}$ & 0.30 \\
September 13, 2007 & 0.886 & $12.03 \mathrm{~km}$ & 0.37 \\
\hline
\end{tabular}

ingly, upriver populations declined dramatically to an average of $<20$ burrows $\mathrm{m}^{-2}$ (Fig. 8).

The consistency in the downriver distribution of adults is concordant with the larval transport model simulation predictions. The transport model predicts that downriver areas receive an uninterrupted supply of megalopae capable of settlement and metamorphosis.

Nonlinear regression models were fit to all 3 population distributions (Table 3). The results of the Uca minax population distribution surveys indicate that on-river populations varied little between seasons or between early season and late season of the same year. It is possible that a 2 to 3 yr life span of $U$. minax buffers against dramatic population fluctuations along the river.

The adult distribution of Uca minax on the Pee Dee River compared favorably with model predictions of expected rates of megalopae settlement (Fig. 7). The actual on-river distribution of adult crabs begins to decrease around $8 \mathrm{~km}$ from the confluence of the Pee Dee and Waccamaw Rivers. The frequency distribution of the model simulations of the 2005 megalopal season peaks between 8 and $11 \mathrm{~km}$ maximum distances traveled. The model simulation frequency distribution drops dramatically farther upriver, predicting a drop in the supply of megalopae being delivered upriver. This drop in the supply of megalopae predicted by the model correlates well with the significant reduction in the density of $U$. minax burrows in the river.

\section{DISCUSSION}

Many organisms inhabit estuaries, and often their survivability depends upon advection during critical stages of their life cycle. Meaningful estimates of transport require accurate models of the flow field. In the upper estuary, the simple channel geometry in many rivers allows the system to be treated adequately as being $1 \mathrm{D}$, especially with respect to poten- 
tial larval transport. Likewise, the dynamics consist of a decaying tidal forcing superimposed on an opposing discharge. We exploited these concepts to develop an analytical model to predict the alongchannel flow in a river with a strong tidal signal. The equations produced a simple analytical formulation that included the effect of friction and opposing river discharge on tidal damping. This led to a larval transport model to completely specify position of a larva/ post-larva as a function of time in terms of only 5 parameters: $u_{0}, u_{\mathrm{a}}, \omega, h_{0}$, and $f$. The first 4 can be measured at a single point in the upper estuary or derived from historical flow databases, which makes the model very easy to apply to a wide variety of tidally influenced rivers. The friction factor is more difficult to measure directly in the field. If measurements are unavailable, we recommend the user consult the literature to obtain a value appropriate for the bed conditions at the study site (e.g. Chanson 2004). Comparisons between measured and modeled along-river gradients in tidal velocity amplitude were statistically significant, providing observational evidence to justify our linearized transport formulations supporting the simple transport formula presented here.

This is by no means the first coupled larval behavior-circulation model that has been developed; however, to our knowledge, it is the first that was designed with the flexibility to predict the dispersal potential of any species for which larval swimming behaviors are understood and has an inland range that penetrates into tidally influenced freshwater.

The models available to adequately approximate physical conditions within a given estuary are often quite complex, consisting of 3D transport models (e.g. Chatwin \& Allen 1985, Heemink 1990, Blumberg et al. 1993, Dimou \& Adams 1993). These types of models are typically data intensive and require high-quality observational data sets that may or may not be available for all estuaries. By necessity, the data collection and modeling process that support the development of these 3D transport models would have to be duplicated for all combinations of estuary and organism. This is a labor-intensive, timeconsuming process, and the fiscal limitations associated with the development of such models remains a serious obstacle to the widespread study of larval transport phenomenon. Additionally, the suite of models currently available does not address larval transport within the freshwater sections of tidal rivers discharging into estuaries.

Our model fills the need for a simple larval transport model that is interactive and requires minimal efforts in data collection in order to be customized for a particular estuary and organism-specific behaviors affecting larval transport. When our flow model is coupled with FTT behavior of our test organism, Uca minax, we can predict the ability of larvae to recruit back to the freshwater reaches of the Pee Dee River estuary for any combination of river discharges or tidal amplitudes.

Variable but significant river flow that dampens the intensity and duration of upriver tidal flow can limit the successful recruitment of post-larvae and juveniles back to conspecific adult habitats, potentially affecting adult population dynamics. Silva et al. (2006) found that the settlement rates of Carcinus maenas L. (Brachyura, Portunidae) megalopae were highly variable along the longitudinal axis of an estuary in the Mira River Estuary in Portugal. The lower estuary, however, was less variable and had higher megalopa settlement rate. Other investigators have observed similar patterns of spatial heterogeneity of settlement patterns within estuaries along the Atlantic and Gulf coasts of the USA (Olmi et al. 1990, Boylan \&Wenner 1993, Wrona et al. 1995, Morgan et al. 1996, Hasek \& Rabalais 2001).

Within the Winyah Bay-Pee Dee River system, we see a very similar pattern with Uca minax adult distributions. In our study, we used adult distribution as a proxy for megalopal recruitment rates. Because $U$. minax exercises an export strategy for early life stages (zoeae) and larvae develop in coastal waters before reentering estuaries, adults living in the brackish and freshwater sites would have originated from the same post-larval pool entering Winyah Bay 1 to 3 yr earlier.

The relatively consistent adult population densities of Uca minax along the Winyah Bay-Pee Dee River estuary demonstrate a lack of attenuation of megalopae in the lower estuary. Adult populations downriver, closest to the confluence with Winyah Bay, have less variability and are found in higher densities than upriver populations. Our larval transport model is predictive of this. Model predictions of the maximum upriver excursion of a megalopa that rides only the nocturnal flood tide compare well with the current upriver distribution of adult $U$. minax, confirming the model's usefulness as a tool in understanding recruitment patterns. We did make some simplifying assumptions in estimating the $U$. minax population density gradient along the Pee Dee River. Firstly, we assumed that settlement was random and specific settlement cues were equal along the length of the river. Secondly, we assumed there is no difference in post-settlement selection pressures along the river 
channel that would account for differences in population distribution. This assumption seems valid, as the flora and fauna found along the river banks and the adjoining floodplain forests are quite similar within the study area.

We believe that our flow and transport model presents a clearer picture of Uca minax recruitment dynamics in a part of the estuary largely ignored in the literature. Our model allows us to both forecast and hindcast upstream larval migration potential of estuarine species with catadromous larval and juvenile migration behaviors. This tool advances our understanding of recruitment of such species under natural as well as human-mediated alterations of river flow. Therefore, the model allows users to examine the possible effects of river flow management decisions on species distributions within a watershed.

Potential human-induced changes in flow (from increased upriver water withdrawal) or eustatic sea level rise (due to effects of global warming) will amplify the intensity and duration of flood tidal currents that transport marine larvae upstream, increasing inland penetration to previously unoccupied habitat. The ecological consequences of such changes in flow are largely unknown. For example, the presence of Uca minax in new freshwater habitats can have a significant impact on other species' distributions as well as trophic dynamics. U. minax megalopae, juveniles, and adults, at a minimum, represent a tidally mediated special supplement to the tidal freshwater marsh food webs. As a deposit feeder, $U$. minax would provide a very significant energy transfer link (as prey) between the detrital food web and the grazing food web that was previously unavailable to predators found in tidal freshwater (mammals, reptiles, birds, fish) systems. Additionally, $U$. minax, through its burrowing activity, may serve as an 'ecosystem engineer' by modifying local soil/ sediment conditions (i.e. aeration, increasing erosion, increasing sediment surface area, altering sediment redox conditions, altering nutrient flux). In the Winyah Bay estuary as well as other river-dominated estuaries on the southeastern coast of the USA (i.e. Savannah River, Altamaha River), U. minax adult populations in tidal freshwater far outnumber those in the mesohaline lower estuary. U. minax is one of the most abundant macroinvertebrates in these habitats, serving as prey for many carnivores.

During the reproductive season, sexually mature Uca minax females release their zoea larvae into the river on nocturnal spring ebb tides for subsequent transport down-estuary and presumably into coastal marine waters where development continues. These planktonic larvae are heavily grazed upon by a variety of planktivorous predators (Morgan 1986, 1990, Morgan \& Christy 1997). Larvae leaving these tidal freshwater habitats represent a significant point of energy transfer from freshwater systems to estuarine and, potentially, marine food webs.

Model predictions of maximum upriver excursion potentials of Uca minax megalopae can be further refined and calibrated by running model simulations using actual river flow and tidal amplitude data available for the Pee Dee River. Upriver penetration also depends on the number of tidal cycles exploited by a megalopa. Therefore, the length of time a $U$. minax larva spends in the megalopal stage can affect its upriver migration potential. Since larval development varies with water temperature, we plan to add a larval development time function for U. minax into the model that accounts for varied water temperatures over a larval season.

The model can be used to predict upstream migration potential of megalopae exploiting flood tidal currents as well as downstream migration potential of zoeae utilizing an export strategy by riding ebb tidal currents downstream. The model may be even more useful if linked with other flow models in the lower estuary and nearshore to provide a more complete understanding of the dispersal of marine and estuarine larvae as a whole. Other estuarine models that include salinity and mixing could be used to supply input into our model to provide extra functionality for potential end users.

The flow/larval transport model we developed can be used to assess the potential impacts of changing river flow and sea level on larval recruitment and dispersal of many types of planktonic larvae to upstream areas of coastal rivers. The model may be used by scientists, resource managers, and stakeholders when making decisions about minimum river flow allocations. Tools to assess the ecological impacts of decreasing river flow are currently lacking. The simple formulation presented here, combined with its demonstrated accuracy for predicting species habitat boundaries, makes this model attractive to a wide user base without requiring a firm background in computational fluid mechanics.

Acknowledgements. This work would not have been possible without the input, criticism, and labor of J. Staton, R. Tankersley, J. Christy, D. Wethey, J. Jurissa, S. Trynum, H. Bull, R. Bier, J. Mraz, K. Butler, P. Lopez-Duarte, J. Jost, P. Brannock, M. Sutton Tabor, M. Flenniken, C. Borgianini, and the scientists and staff of the Baruch Marine Field Lab- 
oratory. This work was supported by the National Science Foundation Grant IOB-0237484 (Colonizing land via the estuarine route: ontogeny of osmoregulation and settlement behaviors in three brackish water fiddler crabs).

\section{LITERATURE CITED}

Anger K (2001) The biology of decapod crustacean larvae. Crustacean issues, Vol 14. A.A. Balkema, Lisse

Anger K (2003) Salinity as a key parameter in the larval biology of decapod crustaceans. Invertebr Reprod Dev 43: 29-45

Behum ME, Brodie RJ, Staton JL (2005) Distribution of juvenile Uca pugnax and $U$. pugilator across habitats in a South Carolina estuary, assessed by molecular techniques. Mar Ecol Prog Ser 288:211-220

Blumberg A, Signell R, Jenter H (1993) Modeling transport processes in the coastal ocean. J Environ Eng 1:31-52

> Boylan JM, Wenner EL (1993) Settlement of brachyuran megalopae in a South Carolina, USA, estuary. Mar Ecol Prog Ser 97:237-246

Brodie RJ, Behum M, Monroe E, Staton J, Glenn N (2005) Recruitment to adult habitats following marine planktonic development in the in the fiddler crabs Uca pugilator, Uca pugnax and Uca minax. Mar Biol 147:105-111

Brodie RJ, Styles R, Borgianini SA, Godley J, Butler K (2007) Larval mortality during export to the sea in the fiddler crab Uca minax. Mar Biol 152:1283-1291

Brookins KG, Epifanio CE (1985) Abundance of brachyuran larvae in a small coastal inlet over six consecutive tidal cycles. Estuaries 8:60-67

Chanson H (2004) The hydraulics of open channel flow: an introduction. Elsevier, Amsterdam

Charmantier GL, Gimenez M, Charmantier-Daures M (2001) Ontogeny of osmoregulation in crustaceans: the embryonic phase. Am Zool 41:1078-1089

Chatwin PC, Allen CM (1985) Mathematical models of dispersion in rivers and estuaries. Annu Rev Fluid Mech 17: 119-149

> Christy JH (1982) Adaptive significance of semilunar cycles of larval release in fiddler crabs (genus Uca): test of an hypothesis. Biol Bull (Woods Hole) 163:251-263

Christy JH, Morgan SG (1998) Estuarine immigration by crab postlarvae: mechanics, reliability, and adaptive significance. Mar Ecol Prog Ser 174:51-65

Christy JH, Stancyk SE (1982) Timing of larval production and flux of invertebrate larvae in a well-mixed estuary. In: Kennedy VS (ed) Estuarine comparisons. Academic Press, New York, NY, p 489-503

Crane J (1975) Fiddler crabs of the world: Ocypodidae: genus Uca. Princeton University Press, New York, NY

> Cronin TW, Forward RB Jr (1979) Tidal vertical migration: an endogenous rhythm in estuarine crab larvae. Science 205:1020-1022

Cronin TW, Forward RB Jr (1986) Vertical migration cycles of crab larvae and their role in larval dispersal. Bull Mar Sci 39:192-201

> DeVries MC, Tankersley RA, Forward RB Jr, Kirby-Smith WW, Luettich RA (1994) Abundance of estuarine crab larvae is associated with tidal hydrologic variables. Mar Biol 118:403-413

$>$ Dimou KN, Adams EE (1993) A random particle tracking model for well-mixed estuaries and coastal waters. Estuar Coast Shelf Sci 37:99-110
Epifanio CE (1988) Transport of invertebrate larvae between estuaries and the continental shelf. Am Fish Soc Symp 3: 104-114

Forward RB, Tankersley RA (2001) Selective tidal-stream transport of marine animals. Oceanogr Mar Biol Annu Rev 39:305-353

> Goni MA, Teixeira MJ, Perkey DW (2003) Sources and distribution of organic matter in a river-dominated estuary (Winyah Bay, SC, USA). Estuar Coast Shelf Sci 57: 1023-1048

Hasek BE, Rabalais NN (2001) Settlement patterns of brachyuran megalopae in a Louisiana estuary. Estuaries 24:796-807

Heemink AW (1990) Identification of wind stress on shallow water surfaces by optimal smoothing. Stoch Hydrol Hydraul 4:105-119

> Horrevoets AC, Savenije HHG, Schuurman JN, Gras S (2004) The influence of river discharge on tidal damping in alluvial estuaries. J Hydrol (Amst) 294:213-228

Johnson DF (1985) The distribution of brachyuran crustacean megalopae in the waters of the York River, lower Chesapeake Bay and adjacent shelf: implications for recruitment. Estuar Coast Shelf Sci 20:693-705

Little KT, Epifanio CE (1991) Mechanism for the re-invasion of the estuary by two species of brachyuran megalopae. Mar Ecol Prog Ser 68:235-242

> López-Duarte PC, Tankersley RA (2009) Developmental shift in the selective tidal-stream transport behavior of larvae of the fiddler crab UCa minax (LeConte). J Exp Mar Biol Ecol 368:169-180

- Macia A, Quincardete I, Paula J (2001) A comparison of alternative methods for estimating population density of the fiddler crab Uca annulipes at Saco Mangrove, Inhaca Island (Mozambique). Hydrobiologia 449:213-219

Morgan SG (1986) The impact of planktivory on the life histories of estuarine crabs. $\mathrm{PhD}$ dissertation, University of Maryland, Cambridge, MD

> Morgan SG (1987) Selection on hatching rhythms and dispersal patterns of estuarine crab larvae: avoidance of physiological stress by larval export? J Exp Mar Biol Ecol 113:71-78

Morgan SG (1990) Impact of planktivorous fishes on dispersal, hatching, and morphology of estuarine crab larvae. Ecology 71:1639-1652

> Morgan SG, Christy JH (1995) Adaptive significance of the timing of larval release by crabs. Am Nat 145:457-479

Morgan SG, Christy JH (1997) Planktivorous fishes as selective agents for reproductive synchrony. J Exp Mar Biol Ecol 209:89-101

> Morgan SG, Zimmer-Faust RK, Heck KL Jr, Coen LD (1996) Population regulation of blue crabs Callinectes sapidus in the northern Gulf of Mexico: postlarval supply. Mar Ecol Prog Ser 133:73-88

O'Connor NJ, Gregg AS (1998) Influence of potential habitat cues on duration of the megalopal stage of the fiddler crab Uca pugnax. J Crustac Biol 18:700-709

O'Connor NJ, Judge ML (2004) Molting of fiddler crab UCa minax megalopae: stimulatory cues are specific to salt marshes. Mar Ecol Prog Ser 282:229-236

O'Connor NJ, Van BT (2006) Adult fiddler crabs Uca pugnax (Smith) enhance sediment-associated cues for molting of conspecific megalopae. J Exp Mar Biol Ecol 335:123-130

Olmi EJ (1994) Vertical migration of blue crab Callinectes sapidus megalopae: implications for transport in estuaries. Mar Ecol Prog Ser 113:39-54 
Olmi EJ, van Montfrans J, Lipcius RN, Orth RJ, Sadler PW (1990) Variation in planktonic availability and settlement of blue crab megalopae in the York River, Virginia. Bull Mar Sci 46:230-243

Pawlowicz R, Beardsley B, Lentz S (2002) Classical tidal harmonic analysis including error estimates in MATLAB using T_TIDE. Comput Geosci 28:929-937

Roughgarden J, Gaines S, Possingham H (1988) Recruitment dynamics in complex life cycles. Science 241: 1460-1466

Silva IC, Dinis AM, Francisco SM, Flores AAV, Paula J (2006) Longitudinal distribution and lateral pattern of megalopal settlement and juvenile recruitment of Carcinus maenas (L.) (Brachyura, Portunidae) in the Mira River Estuary, Portugal. Estuar Coast Shelf Sci 69: 179-188

Editorial responsibility: Steven Morgan, Bodega Bay, California, USA
Skov MW, Hartnoll RG (2001) Comparative suitability of binocular observation, burrow counting and excavation for the quantification of the mangrove fiddler crab $U_{C a}$ annulipes (H. Milne Edwards). Hydrobiologia 449: 201-212

Strathmann RR (1982) Selection for retention or export of larvae in estuaries. In: Kennedy VS (ed) Estuarine comparisons. Academic Press, San Diego, CA, p 521-535

Tankersley RA, Welch JM, Forward RB Jr (2002) Settlement times of blue crab (Callinectes sapidus) megalopae during flood-tide transport. Mar Biol 141:863-875

Teal JM (1958) Distribution of fiddler crabs in Georgia salt marshes. Ecology 39:185-193

Wrona AB, Wiegert RG, Bishop TD (1995) Initial report of settlement patterns of brachyuran megalopae at Sapelo Island, Georgia, USA. Bull Mar Sci 57:807-820

Submitted: August 19, 2011; Accepted: January 14, 2012

Proofs received from author(s): April 8, 2012 